\title{
The Analysis of Aesthetic Perception of Theravada Buddhist Architecture in Xishuangbanna
}

\author{
Qiuying Zhang \\ A College of Marxism, Yunnan Open University, Kunming 650500, China. \\ Corresponding author: 61330531@qq.com
}

Keywords: Xishuangbanna; Theravada Buddhist architecture; aesthetic perception

\begin{abstract}
The aesthetic perception embodied by the architecture is not a touchable object, but the harmony between people's aesthetic taste of architecture and beauty of the buildings themselves. ${ }^{1}$ Enjoying a long cultural tradition, the architectural beauty of Theravada Buddhist temples is rich and varied. In terms of artistic perception, the Theravada Buddhist temples show the beauty of traditional Chinese temples; when it comes to the environment, they reflects the harmony between nature and mankind; as for the styles, they present the beauty of folk houses and religious buildings, which feature profound cultural implications, endowing people with rich aesthetic imagination and impressive academic inspiration.

The Theravada Buddhist temples are a typical kind of ecotype architecture. Generally speaking, architecture refers to the aesthetic space established in a certain cultural atmosphere, which shows the external beauty of such buildings. Compared with general buildings, the Theravada Buddhist temples not only create a solemn religious space, but also exhibit a special regional culture. In addition to the use of eco-friendly materials during the construction, the ecology of Dai architecture is also reflected in its appearances that are compliant with ecological principles or conducive to ecological balance, adopt to the local climate conditions, and demonstrate the spirit of local history and culture. ${ }^{2}$ Therefore, the author firmly believes that the Buddhist architecture of Dai Society can quicken the combination of ecological and architectural systems to a certain extent, and eventually produce the diversified aesthetic feelings.
\end{abstract}

\section{Formal Beauty of Theravada Buddhist Architecture in Xishuangbanna}

The main reason why architecture can be called art is that it constructs a rich and colorful visual frame on the basis of spatial organizations, tones, proportions, textures and other artistic languages, thus demonstrating the beauty of modelling which combines expressiveness and space, creating artistic images and arousing people's emotional resonance. he space environment of Buddhist temples is artificial, so that it is able to satisfy people's material and spiritual needs functionally. Therefore, when studying this kind of architectural art, we should not only seek its practical attribute, but also explore its formal beauty. From the following aspects, the author would like to discuss the formal beauty of the Theravada Buddhist temples in detail.

\subsection{Contraposition and correspondence}

Contraposition actually refers to the reasonable distribution of architectural elements. If the spatial organization, appearance and other elements are under the restrictions of logic, order, etc., it is bound to keep harmony among all of them. In brief, the contraposition is also known as correspondence, and the contraposition between the axes and the sidelines of each element is used to achieve its corresponding relationship generally.

\subsection{Balance and stability}

Balance and stability reflect the harmony and unity of the building, and make it more impressive visually. In contemporary society, people not only pay attention to material life, but also constantly 
pursue the stability and harmony of social atmosphere. The architectural features of balance and stability imply people's pursuit of security and sense of belonging. Chinese scholars tend to carry out in-depth study of the balance and stability from the static and dynamic aspects by the means of imaginal thinking. ${ }^{3}$ This method is very effective in the appearance design of monomer buildings. The traditional Buddhist architecture in Dai Society vary widely in appearances and shapes, for example, some temples are strongly symmetrical, while others have completely asymmetric structures. Generally speaking, in order to create a solemn and sacred feeling of Buddhist temples, the space between the corridor and the hall is often expanded, thus achieving a stunning visual effect.

\subsection{Proportion and scale}

Due to its three-dimensional nature, a building shows unique artistic beauty in different directions. The proportion and scale of the building not only have impact onits overall visual effect, but also closely relate to itscomponents. Whether the proportion is balanced and the scale is reasonable or not, determinesthe harmony and unity ofaentire building. As is known to all, the golden section has always been considered as the most ideal proportion of division, and it is presented in the form of a rectangle. So far, boasting a harmonious proportion and rhythm, as well as the ingenious and vigorous joints, the Buddhist temples in the Dai area of Xishuangbanna are uniform and symmetrical, which can be said to have reached the perfect condition. The scale of each component of the Buddhist temples is different. In general, the main hall is the largest, while the areas of other functional space, such as monk rooms, depositaries of Buddhist texts and scripture halls, are relatively smaller. Such design aims to highlight the solemn sanctity and lofty status of the main hall. Besides, the towering pagoda paints the entire building in a new light, making it even more harmonious.

\section{Decorative Beauty of Theravada Buddhist Architecture in Xishuangbanna}

The decoration is an indispensable part of Buddhist architecture. The decorations of Buddhist temples in Dai area are the fruits of labor and local people's painstaking efforts, which generally featurea strong ethnicflavor.Visitors will not only focus on the overall shapes of Buddhist temples, but also pay special attention to their decorations and furnishings. Theravada Buddhist architecture in Xishuangbanna not only stands out for its slim and graceful architectural styles, but also reflects its aesthetic perception and local characteristics in ingeniousdecorations. Overall, the decorations of Theravada Buddhist architecture is both pleasing to the eye and practical in use, as well as full of the exquisite feelings of the Dai people, which serves as a visual feast to all visitors and a carrier of information and emotions conveyed by the Dai people. The ethnic culture that has a long glorious history has been presented in its architectural styles incisively and vividly. The decorations of Buddhist architecture can be seen everywherein Xishuangbanna. For example, the lifelike paintings and sculptures on the pagoda, and the furnishings of various styles inside the buildings as well,have fully demonstrated the long-standing religious culture of the Dai people.

Buddhist architecture is used to express Dai people's awe of nature, as well as their recognition of and respect for religious culture, and they attach more importance to the inner decorations. Therefore, the main hall of Buddhist temples in Xishuangbanna is often enveloped in a strong religious atmosphere. Whether it ison doors, windows and corridors, or arches and beams, lifelike animal carvings, vivid paintings and glittering gold and silver decorations can be seen almost everywhere, making people feel like entering a luminous world of brilliance. Here, visitors not only feel the solemn Buddhist culture, but also deepen their yearning for Buddhism.In addition, because of the small skylights and flickering oil lamps, the dark indoor environment leads people to feel as if they have entered another country, andexperience a sense of depressioninevitably. In the dim light, the solemn and benevolent image of the Buddha (full face, slender eyebrows and plump figure) becomes even more prominent, as if it had already pierced every earthly trivial. What an admiration.

Although lifeless, the temples convey Buddhist culture to people all the time. Buddhist 
architecture introduces people to the brightness of Pure Land, and at the same time,emerges themintothe hardships of real life.Inside the Buddhist temples, avariety of vivid murals can be seen, describing the stories of heaven, telling the eternal cycle of birth and death, publicizing the retribution of good and evil, or carving the stories of asceticism. On the one hand, they create an ideal country of Buddhism; on the other hand, they exhort more people to become its followers.

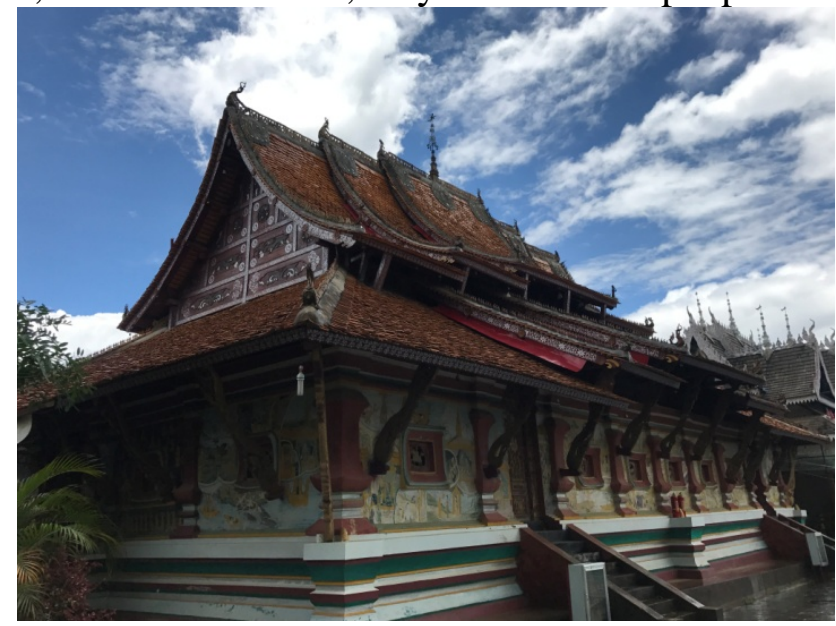

Fig.1 Mandou Buddist temple of Xishuangbanna(Author’s photography)

\section{Color Schemes of Theravada Buddhist Architecture in Xishuangbanna}

Color is an important part of sight, which creates a certain atmosphere for a building together with other visual elements and conveys emotions and information to people. As an independent visual element, color is likely to make the emotions more distinct.

Colors, whether given by building materials or by human beings, have a lively and rich expressive force and certain symbolic meaning.Bright colors are widely used in Buddhist temples, which aim to increase the dynamic and aesthetic properties of the buildings. Although the building materials have their own colors already, Buddhist temples often modify the original colors of raw materials for the sake of beauty and transmission of symbolic meaning. In most cases, the Theravada Buddhist temples and pagodas in Xishuangbanna are located in the forests, beside the highways, in the fields and against the mountains, which draw lovely landscape paintings by setting off the surrounding environment. Towering buildings, brilliant decorations and lifelike carvings and paintings make the Buddhist temples look more solemn and sacred, giving people a sense of magnificence.

Colors undoubtedly play the main role amongall artistic elements of TheravadaBuddhist architecture in Xishuangbanna.For visitors, the first thing to catch their eyes is the various colors of Buddhist temples. Whether the colors of building materials and decorations match reasonably or not, determines the visual experience of visitors.Skillful color processing can not only enhance artistic beauty, but also stimulate the imagination of visitors, thus fusing the virtual dreams with the real world.When visitors stand in front of the a Buddhist temple, the very first thing that comes into view is the brilliant colors, rather than the structure and appearance of the entire building. With its excellent expressive force and strong sense of space, color can affect people's thinking modes and visual perception, thus determiningpeople's overall feelings of a building. In order to create an atmosphere of warmth and harmony, the architectural tones of most TheravadaBuddhist templesare warm colors, and the cool colors are used less frequently. Warm tone expresses the Dai people's hospitality and simplicity. ${ }^{4}$ In local culture, the reddish color represents festivity, and the yellowish color symbolizes wealth and dignity, consequently, Buddhist temples in Dai area of Xishuangbanna take these two colors as the main tones.

The use of golden (yellowish) color has different cultural meanings in the architectural decorations of Theravada Buddhist architecture. The Dai people living in Xishuangbanna hold that the best color is gold, which represents nobility and wealth. In Xishuangbanna, the Dai and Blang 
peoples, who believe in Theravada Buddhism, have achieved their good wishes of benevolence by donating gold and silver to temples and praying for prosperity and happiness in the next life. From the environmental point of view, the Dai area is rich in gold and have commercial activities of certain scales, consequently, gold and silver are equal to something precious, which is one of the reasons why they use gold to decorate (or even exaggerate) things. In addition, although the corps in Dai area, such as rice, banana, mango, etc., go ripe in different times, they turn yellow without exception at the right seasons. The Dai people live and work in such agolden world, and yellow has become a symbol of harvest. Therefore, the Dai people prefer to use yellow to express their pursuit of a better life, and respect for and worship of mother nature. In Xishuangbanna, a large number of Dai people have become Buddhists, and yellow is the most popular color of Buddhism. The Dai people believe that the harvest season comes when the Bodhi trees blossom, and the golden glow shone on the entire tree symbolizes a steady flow of vitality and energy. Yellow, as the original color of soil, is frequently used in Dai Buddhist architecture and residential decorations, implying that the Dai people respect the natural law of harmony between mankind and nature. Taking yellow as the basic color of Buddhist temples not only shows respect to nature, but also expresses the good wishes of the Dai people, indicating that the ethnic group has always linked its own destiny with that of the whole nation. Many Dai people who live on farming believe in the harmony between nature and mankind, and keep a close tie with the yellow soil that can not be cut off. People, who cultivate on and harvest from the land, have already assimilated with the yellow land. Therefore, in the mind of the Dai people, yellow is a sacred color that implies vitality and harvest, and to this end, it is often used in the Theravada Buddhist architecture.

In terms of the color itself, yellow is a bright color that can instantly arouse people's attention. Besides, it is more moderate than reddish color and full of vitality, giving people a sense of relaxation, positiveness and comfort. Because of its low chromaticity and brightness, it is a kind of simple and cheerful heavy color.

As a color that is favored by the Dai people in Xishuangbanna and is frequently used in Buddhist temples, yellow conveys the feelings of the Dai people. At the same time, white and red are often seen in the Theravada Buddhist architecture. For example, the white pagoda implies the purity of Buddha, and the white lotus is often used as a symbol of Buddhism. Skillful color matching and handling techniques fully demonstrate the wisdom of the Dai people, the application of architectural colors also reflects their aesthetic perception. Although a variety of colors have been used in the one same building, some of which are even quite contrasting, their common purpose is only to make the harmonious religious atmosphere more rich and pleasing, and the artistic expressions more consistent withpractical contents.

\section{Conclusion}

The TheravadaBuddhist templeis a kind of diversified and multi-functional aesthetic object, and its aesthetic characteristics is introverted to a certain extent.In addition to technology and craftsmanship, it also covers the fields of art, ecology, culture, religion, etc.. The Theravada Buddhist temple exhibits the unique generous culture of the Dai ethnic group in Yunnan, and embodies the principle of common progress and the spirit of peaceful coexistence. Only by maintaining a generous and kind heart, can people truly achieve the principles of common progress and peaceful coexistence, and form a harmonious relationship among society, mankind, other living creatures and Mother Nature.

\section{References}

[1] Jing Qimin. Ecological Architecture [J], Architectural Journal, 2000, 32(7):6.

[2] Cai Zhenjue. Ecological Spirit of Chinese Dwellings [J], Architectural Journal, 1999, 7:47-50.

[3] Si Xinzhi. Study of National Architecture of Southwest China [M]. Kunming: Yunnan Educational Publishing House, 1992. 
[4] Cao Chengzhang. Study of Dai Society[M]. Kunming: Yunnan People’s Publishing House, 1988.

[5] Liu Hengjian. On the Original Character of Ecological Aesthetics -- Ecological Aesthetics: A New Visual Field [J]. Xi'an: Journal of Shanxi Normal University (Philosophy and Social Science), 2001, 2.

[6] Yang Xin, Gan Lin. Aesthetics Principles [M]. Beijing: Peking University Press, 2001.

[7] [Germany] Georg Wilhelm Friedrich Hegel. Aesthetics: Lectures on Fine Art [M]. Beijing: The Commercial Press, 1979.

[8] Zhu Liyuan. Modern Western Aesthetics [M]. Shanghai, Shanghai literature and Art Publishing House, 1993.

[9] Zhong Dekun. The Relationship between Old and New Buildings in Architectural Environment [J]. Postgraduate Dissertation of Southeast University.

[10] Xu Renyao, Wang Xiaoli. Architecture of the Ethnic Groups in China [M]. Beijing: Minzu University of China Press, 1999. 